\title{
Interviewing Successfully for Academic Positions: A Framework for Candidates for Asking Questions during the Interview Process
}

\author{
Anthony J. Onwuegbuzie ${ }^{1, *}$ \& Eunjin Hwang ${ }^{1}$ \\ ${ }^{1}$ Department of Educational Leadership and Counseling, Sam Houston State University, \\ Texas 77341-2119, USA \\ *Corresponding author: Department of Educational Leadership and Counseling, Box 2119, \\ Sam Houston State University, Huntsville, Texas 77341-2119, USA. E-mail: \\ tonyonwuegbuzie@aol.com
}

Received: October 17, 2013

Accepted: April 22, 2014 Published: May 29, 2014

doi:10.5296/ije.v6i2.4424

URL: http://dx.doi.org/10.5296/ije.v6i2.4424

\begin{abstract}
The interview perhaps is the most influential factor in the academic employment process. Although curriculum vitae, cover letters, and recommendations are essential aspects that typically determine whether the candidate will be invited for interview, the on-site interview typically is the final determining factor in the selection process. Hence, during the interview process, candidates should convey not only academic/professional strengths but also collegiality in an appropriate manner. Asking appropriate questions during academic interviews is essential in that it allows applicants to detect what is expected from departments or units and also provides applicants with valuable information to assess the best fit. However, an extensive review of the literature revealed no work that discussed explicitly the types of questions that interview candidates should pose. Thus, the major purpose of this article is to provide a framework for candidates who seek academic positions for asking questions during the interview process. In particular, typologies of interview questions are provided. Additionally, numerous questions are presented that are classified as being related to teaching, research, and service. Further, these questions are sub-divided into questions for search committee members, the department chairperson/unit leader, dean, and vice president/provost. Although the list is by no means exhaustive, it is hoped that it will help candidates view the academic interview as a two-way process in which both parties assume the joint role of interviewer and interviewee.
\end{abstract}

Keywords: interviewing, academic positions, job talk, interview preparation, interview questions, interview presentation, nonverbal communication 
The interview perhaps is the most influential factor in the academic employment process. Although curriculum vitae, cover letters, and recommendations are essential aspects that typically determine whether the candidate will be invited for interview, the on-site interview typically is the final determining factor in the selection process (Kisamore, Casper, Martin, \& Hall, 2004). Hence, during the interview process, candidates should convey not only academic/professional strengths but also collegiality in an appropriate manner.

Academicians involved in the interview process use the personal interview to confirm or to negate impressions conveyed by their curriculum vitae, supporting documents, and recommendations. University personnel also will attempt to assess the candidate's personality and to evaluate her/his potential as a professional colleague. These individuals take several aspects into account when deciding to recommend a candidate for an academic position, including communication skills, knowledge of subject area, enthusiasm, passion, and appearance.

\section{Anxiety in the Job Interview Process}

In the world of academe, interviews for faculty positions involve a multi-stage selection process that typically takes longer than is the case for most other job interviews (Ezell, 2002; Stasny, 2001). Indeed, these interviews often take at least one full work day and often go into a second day because interview candidates are expected to be interviewed by several members of the institution - from faculty members within the interview candidate's unit (e.g., department, college) to one or more representatives of the higher echelons of administration (e.g., university president, vice-president, provost) (Stasny, 2001). Consequently, anxiety is rife during academic job interviews (Young, Behnke, \& Mann, 2004).

In the job interview situation, applicants are evaluated by interviewers who typically are strangers. Hence, the interviews generally are not under the applicant's control and the display of anxiety can be associated with negative outcomes (McCarthy \& Goffin, 2004; Sieverding, 2009). According to Cook, Vance, and Spector (2000), applicants who display lower levels of anxiety are more likely to be invited for a second interview. Further, McCarthy and Goffin (2004) found that interviewer-rated applicant anxiety levels and interviewer-rated applicant performance were negatively related. In other words, applicants who gave the impression that they were anxious were less likely to perform well during interviews. Another interesting finding in this area was the small relationship found between self-ratings and interviewer ratings of anxiety (McCarthy \& Goffin, 2004). This finding implies that self-perceived anxiety levels of interviewees do not correspond necessarily with interviewers' perceptions of interviewee anxiety levels. This finding is useful for job applicants with high levels of anxiety during job interviews because it suggests that they could be counseled through trainings or practices in ways that they can learn to hide their anxiety levels from interviewers, thereby possibly increasing the chances for successful job interview outcomes. 


\section{Personality and Interview Preparation}

An applicant's personality also can affect interview outcomes. Researchers have examined the relationship between the personality of applicants and how they prepare and search information for upcoming interviews. For example, Schmit, Amel, and Ryan (1993) associated the Big Five personality markers with how individuals search for jobs. They found that Conscientiousness, Agreeableness, and Openness to Experience were positively related to assertiveness in searching for jobs. Similarly, Caldwell and Burger (1998) studied how personality influences the way that individuals prepare for a job search, specifically based on the Big Five dimensions. They found that individuals on the high end of the Conscientiousness and Openness to Experience dimensions probably engaged in an extensive amount of information gathering in terms of job-seeking process, potential employers, how to interview, and so on (Caldwell \& Burger, 1998). Additionally, Conscientiousness was positively associated with level of Social Preparation and level of Background Preparation (Caldwell \& Burger, 1998). Furthermore, Extraversion and Openness to Experiences had positive associations with Social Preparation (Caldwell \& Burger, 1998),

Caldwell and Burger (1998) declared that collecting information about the underlying academic position is one of the important ways in which applicants prepare for job interviews. Furthermore, Caldwell and O'Reilly (1985) concluded that how individuals seek out information about job interviews should be associated with their successful outcomes if the source of information that they are consulting is accurate. Findings from these studies implied that collecting information thoroughly and extensively is crucial for successful job interviews even though each one has a different way of doing so depending on his/her personality. Because it would allow applicants to determine the extent to which they fit for the job requirements and also to differentiate themselves from other applicants, as suggested by previous researchers, applicants could even make sure that the information that they have obtained prior to the interview is correct by asking questions to interviewers during the interview and taking the opportunity to evaluate the job opportunities (Barbera, Carr, \& Sasaki, 2004; Boehm-davis, 2004; Kisamore et al., 2004).

\section{Keys to Success when Applying for a Job in Academia}

There are multi-faceted recruitment stages (e.g., interview, job talk, formal meeting) in the selection process for academic positions. A few authors have provided useful tips and guidelines for successful performance at each stage of the hiring process (e.g., interview/site visit, job talk) when applying for a job in academia (Barbera et al., 2004; Boehm-davis, 2004; Gaugler, 2004; Kisamore et al., 2004). Some of these tips and guidelines are presented in the following section. 


\section{Interviews}

Boehm-davis (2004) contended that both the search committee members and job applicant should be involved in assessing the fit during an interview. Specifically, search committee members should determine whether the applicant is the best fit for the position and competent with depth of knowledge. In the meantime, the applicant should use the interview to determine whether the working environment (i.e., working styles, physical layout, locale, values, opportunities for collaboration, teaching loads) fits his/her work style and career goals. Because selection is a two-way process, asking questions is essential in that it allows applicants to detect what is expected from departments or units and also provides applicants with valuable information to assess the best fit (Barbera et al., 2004; Boehm-davis, 2004; Kisamore et al., 2004). Therefore, candidates might be engaged more actively in the interview process by asking appropriate questions to evaluate the job opportunities.

There are two types of interviews: phone interview and site visit (Kisamore et al., 2004). Whereas the goal of the phone interview is to narrow the applicant pool to a few candidates who will be brought to onsite interviews (Kisamore et al., 2004), the goal of the site visit/interview is to assess further whether the applicant is a good fit for the underlying department or unit (Barbera et al., 2004). For the phone interview, Kisamore et al. (2004) advised that applicants be prepared for interview questions and answer them succinctly, emphasizing how one's background fits the position. On the other hand, social skills play a greater role in successful performance for the site visit/interview (Kisamore et al., 2004) because subjective factors (e.g., dress, attitude, physical appearance, nonverbal communication cues) that can create either positive or negative images can be involved in the decision-making process (Galassi \& Galassi, 1978). Accordingly, it was advised that applicants should dress professionally, but conservatively (Galassi \& Galassi, 1978; Kisamore et al., 2004), and play an appropriate role as a new faculty member, not a graduate student (i.e., not being overly causal or formal with students; Barbera et al., 2004).

Other suggestions were recommended for preparing for interviews as follows: (a) research the program (i.e., structure, faculty, administrative, recent research areas) by using diverse resources (i.e., websites, personal contact); and (b) prepare a set of meaningful and appropriate questions that can be used to assess the fit (Barbera et al., 2004; Boehm-davis, 2004; Kisamore et al., 2004). We will outline potential questions later in this article. Conversely, there were pitfalls that should be avoided during the interview. For example, appearing narrow or inflexible, demonstrating unrealistic confidence, and believing that the interviewee is not always judged when being in information setting (e.g., at dinner) and/or in meeting with students or other faculty members should be avoided (Barbera et al., 2004).

Job talk. As part of the interview, the candidate might be required to provide a short presentation on a selected topic. This presentation is known as the job talk. The job talk is one of the centerpieces of academic interviews, especially for a research-focused position, which allows faculty members an opportunity to assess applicants' presentation/teaching skills, and learn about the interview candidate's research agenda (Gaugler, 2004; Kisamore et al., 2004). Regarding the stage of preparation for research presentations, the following suggestions have 
been offered by authors: (a) allocate time for the talk and questions appropriately, (b) prepare attractive presentation materials (i.e., graphs, text) to convey the selected content effectively, (c) tailor your talk to diverse audience as needed to fit their knowledge levels, (d) prepare for likely questions, (e) have back-ups for emergencies, and (f) practice your talk in front of a critical audience to be prepared to address any major criticisms (Barbera et al., 2004; Boehm-davis, 2004; Gaugler, 2004; Kisamore, 2004). Furthermore, Kisamore et al. (2004) offered general tips on how candidates can demonstrate their research presentation skills effectively, as follows: candidates should (a) begin their job talk with a brief one-slide demonstration of their research program including research interests, types of research, and multi-faceted characters; (b) discuss research studies most relevant for the position that they have conducted; (c) blend results and discussion in an integrated manner; and (d) include concluding slides for summarizing key findings and linking their research implications to the goals or objectives of the program of research.

Many candidates use parts of their dissertations or other completed research. It is important for candidates to be as professional as possible, which includes considering such items as visual aids and other media resources (making certain in advance that such resources are available to them and will be set up). It is a good idea for candidates to ascertain the maximum size of the audience expected. If possible, they should bring handouts with them. It is imperative that candidates show enthusiasm for the work they are presenting. They should emphasize the importance of their works and their contribution to their fields. Candidates should not allow their presentations to last longer than the allotted time. Also, they should ensure that they leave time for questions from the audience. Candidates should be prepared to answer questions at any time during their presentations, as well as to show appreciation for any questions asked, regardless of the quality of the question. Candidates should be cognizant of the fact that their presentation should be the same quality as a presentation they would give at a professional meeting. Simply put, the goal of candidates is to use the presentations to sell themselves. Indeed, this might be the only criteria that the search committee uses to assess candidates' competence both as a teacher and a researcher.

It is also a good idea for candidates to bring bound copies of any proposals or completed works they have written in the past, which they consider to be of good quality. These works can be research articles, opinion articles, or the like. This, hopefully, would help to convince the interviewers of their commitment to research. If they have taught before, whether at primary, secondary, or tertiary level, it is advisable for candidates to bring samples of student work.

In addition to the research presentation, applicants might be asked to demonstrate live their teaching skills. Kisamore et al. (2004) provided suggestions for conducting an effective teaching presentation as follows: (a) obtain information regarding students so that the candidates can modify their detailed knowledge to appropriate levels; (b) if a choice is given, they should choose a topic with which they are already familiar; (c) if they are assigned a topic, they should learn everything they can about the topic; (d) they should not be afraid to state, "I do not know" if they cannot entertain an audience member's question; and (e) they should ask about the types of equipment that will be available for the teaching presentation. 
Formal dinner inviting. The formal dinner provides the search committee an opportunity to assess the applicant's interpersonal skills. As Barbera et al. (2004) indicated, applicants still are being judged by faculty members whom they meet even during the formal dinner. However, faculty members attempt to learn more about the kinds of people with whom they could be working (Barbera et al., 2004). Hence, applicants should make every effort to enjoy the dinner event and to relax while communicating with faculty members and sharing their personal interests with other faculty members. This event would provide a good opportunity for applicants to demonstrate that they are able to work well in a team.

\section{The Role of Questions during Interviews}

Questions posed by the job candidate play a crucial role in the interview process. In fact, asking good questions often can lead to desirable outcomes for the interview candidate by fulfilling one or more of the following purposes. First and foremost, good questions enable candidates to obtain information from faculty members/administrators that they could not obtain directly (e.g., from the institution's website). For example, good questions can provide the candidate with additional information regarding the faculty members'/administrators' philosophies, short- and long-term academic goals, level of commitment, ability to cope with pressure, and level of organization. Second, good questions - such as those that identify important missing information from the institution's website-give a clear message to interviewers that the candidate has prepared extremely well for the interview by meticulously reading all available information, which, in turn, demonstrates the candidate's interest in and enthusiasm for the position. Third, good questions allow the candidate to probe more deeply into certain issues pertaining to the unit (e.g., department, college, institution), thereby enabling them to determine whether the academic position meets their needs. However, although some exemplars of interview questions exist for search committee members and the like to use for candidates (see, for e.g., http://www.provost.iastate.edu/resources/guide/appendices/appendix-5), an extensive review of the literature revealed no work that discussed explicitly the types of questions that interview candidates should pose. Thus, the purpose of the remainder of this article is to provide a framework for candidates for academic positions for asking questions during the interview process.

\section{A Framework for Asking Important Questions during Interviews}

Using the framework of Denham and Onwuegbuzie (2013), who, in turn, built on the framework of Greene, Caracelli, and Graham (1989), interview questions allow candidates to (a) corroborate information from two or more faculty members/administrators (i.e., triangulation) either concurrently (i.e., by asking the same question to multiple interviewers who are conducting the interview at the same time such as when search committee members interview the candidate as a group) or sequentially (i.e., by asking the same question to multiple interviewers at different times during the interview process; (b) capture overt or 
subtle messages (i.e., complementarity); (c) discover responses made by one or more faculty members/administrators that contradict responses made by one or more other faculty members/administrators (i.e., initiation); (d) broaden the scope of the understanding of a policy, practice, or issue (i.e., expansion); and (e) create new directions based on additional insights (i.e., development). This conceptual framework indicates that candidates can ask questions during the interview process for one or more of five purposes that arise either a priori (e.g., looking for contradictions among faculty members/administrators from the onset), a posteriori (i.e., determining how the responses from various faculty members/administrators relate to each other as the interview unfolds), or iteratively (i.e., combining information extracted from a priori and a posteriori questions). The major point regarding this conceptual framework is that asking good questions can yield valuable information (i.e., obtain thicker descriptions; Geertz, 1973) that will facilitate meaning making on the part of the candidate and, therefore, facilitate decision-making should the candidate subsequently receive a job offer. Using this conceptual framework also should remind candidates that they are not the only ones who are being interviewed-they are also interviewing the faculty members/administrators at the institution!

\section{Types of Questions}

Interview candidates should use both closed-ended and open-ended questions. Closed-ended questions typically are asked for the purpose of obtaining specific information from faculty/administrators. In contrast, open-ended questions are asked for the purpose of obtaining broader information, as well as for obtaining information about perceptions, beliefs, and experiences. Essentially, candidates have at their disposal three types of questions that they can pose to interviewers: main questions, probing questions, and follow-up questions (cf. Rubin \& Rubin, 2005). Main questions provide the scaffolding of the candidate's interview questions. These questions ensure that the most important questions of interest to the candidate will be posed.

Follow-up questions are specific to the previous comments made by the interviewers. These questions are essential for obtaining depth and detail, as well as for obtaining more nuanced answers. Follow-up questions can take various forms, including the following: (a) comparison questions, in which the candidate asks the interviewer(s) to compare two or more elements that were previously discussed (e.g., "How would you compare students who enroll in the face-to-face section of your course and those who enroll in the online section of your course?”); (b) specific questions, wherein the candidate asks for more details by pointing out what seems to be missing in a statement(s) made by the interviewer(s); (c) general questions, whereby the candidate asks the interviewer(s) about implied or actual contradictions; (d) exceptions-to-the-rule questions, in which the candidate asks the interviewer(s) to delineate the conditions under which a generalization made by the interviewer(s) holds (e.g., "As far as you know, do all new faculty members receive a brand new computer?”) such that if an exception to the rule is given by the interviewers, the candidate can follow up further to find out what makes the exception different; and (e) challenge questions, wherein the candidate 
(tentatively and cautiously) asks the interviewer(s) a question that challenges statements made by the interviewer(s) (e.g., "Some faculty members have informed me that class sizes in the department are no larger than 20, whereas other faculty members have informed me that class sizes can be larger than 20; which information is accurate?”).

Probing questions (i.e., probes) are questions asked by the candidate to keep a discussion going while providing clarification. These questions are asked so that interviewer(s) continue talking on the topic at hand, expand on an idea, complete a missing piece of information, or request clarification of what was stated. Moreover, asking probing questions are ways that a candidate can prevent the interviewer(s) from not providing sufficient detail, as well as to encourage people the interviewer(s) from proferring a variety of answers with sufficient detail. When appropriate, the candidate should consider utilizing the following probes: (a) explanatory probes (i.e., probing for reasons); (b) clarificatory probes (i.e., probing to clarify terms and to explore language; to clarify details, sequences, etc.; to clarify through testing an expressed position; challenging inconsistency); (c) elaboration probing (i.e., asking the interviewer(s) for more detail or explanation of a particular concept or theme that emerged from what the interviewer(s) stated; (d) continuation probing (i.e., encouraging the interviewer(s) to keep talking on the present topic using utterances such as "Mmmm mmmm" and "So...”); (e) attention probe (i.e., letting the interviewer(s) know that the candidate is listening carefully for the purpose of encouraging the interviewer(s) to elaborate); (f) steering probing (i.e., leading the interviewer(s) back to the intended path using statements such as "I am sorry I distracted you with my story, can you please continue what you were saying?”); and (f) in-depth, iterative probing (i.e., asking a series of probes until saturation appears to have been reached) (Legard, Keegan, \& Ward, 2003). Good probing does not only resemble good detective work (Legard et al., 2003), but it also represents an effective interview technique.

Alternatively, candidates can use Paul and Elder's (2006) taxonomy of Socratic questions to formulate their questions. Paul and Elder's (2006) taxonomy comprises the following six categories of questions: (a) questions for clarification (e.g., "Could you please explain this further?”), (b) questions that probe assumptions (e.g., Am I correct in concluding that you assume that...?”), (c) questions that probe reasons and evidence (e.g., "What has led you to this conclusion?"), (d) questions about viewpoints and perspectives (e.g., "What effect would that have?”), (e) questions that probe implications and consequences (e.g., "How can I find out?"), and (f) questions about the question (e.g., "Is this the most important question facing your department, or is there another question that is more important?"). These categories build upon each other, but they are not necessarily hierarchical. Rather, a response to a candidate's question might lead into another category of questioning not predetermined by the candidate.

Candidates should refrain from asking leading questions, multiple questions, long-winded or complex questions, and questions that generate yes or no responses (except to [re]structure a response to ensure that an issue is discussed to a required or appropriate level of detail or specificity). Also, candidates should avoid using the word Why in their interview questions because it might unnecessarily put the interviewer(s) on the defensive. Further, candidates 
should avoid critiquing any responses or completing the interviewer's response (Legard et al., 2003). Instead, whatever type of questions asked, candidates should ask short and clear questions, and turn assumptions and other biases into questions.

Following is a list of questions to consider asking various parties during the interview process.

\section{Relevant Questions for Search Committee Members}

The interview session with members of the search committee often is the first formal interview session (or at least one of the first interview sessions) of the day. It usually lasts between 30 minutes and 90 minutes. Because these are the individuals with whom the candidate will be working most closely if he/she accepts a position there, it is important that the candidate declares all of her/his relevant philosophies, aspirations, and goals to this group of people. The following questions should be considered:

\section{Teaching}

(1) When does the fall term begin?

(2) What is the ratio of face-to-face to online courses that I will be expected to Teach?

(3) How many credits are awarded for the course that I will be expected to teach?

(4) What teaching load can I expect to have?

(5) How long does each teaching session last?

(6) What is the ratio of graduate to undergraduate courses that I will be expected to teach?

(7) What is the background of students I would be expected to teach with respect to year of study and major?

(8) What is the range of class size I can expect?

(9) What is the role of faculty in scheduling courses?

(10) Are there any departmental textbooks for the courses I will be expected to teach? If so, which ones?

(11) How much flexibility can I expect to have with respect to selecting (alternative) textbooks?

(12) How much flexibility can I expect to have for selecting course content/material?

(13) How much flexibility can I expect to have with respect to teaching style and the use of 
teaching aids?

(14) What teaching aids/resources would be available to me?

(15) What is the departmental policy on photocopying teaching material?

(16) How much scope is there for obtaining other relevant teaching aids?

(17) What are the requirements for office hours?

(18) How much flexibility can I expect to have for teaching summer school courses? What is the maximum number of courses that I can expect to teach at summer school?

(19) Can I expect to have any graduate assistants at my (part) disposal?

(20) What would my role be with respect to advising students working on their dissertations/theses?

(21) Do students have the opportunity to evaluate my teaching? If so, what is the format of these evaluations and how regularly are they administered?

(22) What weight do these evaluations have with respect to my application for promotion/tenure?

(23) What is the scope for off-site teaching?

(24) Is any form of peer review/evaluation in operation?

(25) How much flexibility can I expect to have with respect to teaching other courses in the future?

(26) How much weight does teaching have in relation to research and service?

(27) Does the promotion/tenure review board incorporate portfolio assessments?

(28) What are the teaching goals of the department and to what extent are they being realized at present?

(29) What is the length of time that must elapse before I can apply for promotion/tenure?

(30) Do I have to apply for tenure and promotion at the same time?

(31) Do you have a "fast" track tenure system?

\section{Research}

(1) What are the expectations of the department with respect to research?

(2) How much emphasis is put on research in relation to teaching and service?

(3) How is research reviewed annually? 
(4) How much and what types of departmental support are allocated to research?

(5) What scope is there for me to write grants?

(6) What support is available to assist me in writing grants?

(7) Are there any research funds available for new faculty members?

(8) How much contact, with respect to research, is there between the department/university and the public schools and local community?

(9) What computer services/technology/library resources are at my disposal to assist me with my research endeavors?

(10) What equipment can I expect to have in my office to assist me in my research endeavors?

(11) Is there some kind of sponsored research program unit? If so, what is their role?

(12) What are the expectations of the department for grant-writing?

(13) To what extent is co-authorship encouraged?

(14) How much weight do joint publications have with respect to the annual professional activity report?

(15) Are travel expenses provided for professional meetings? If so, how much is allocated?

(16) Would I be able to attend the most relevant annual professional meetings for my field, even if it took place during the regular semester/quarter? If so, how easy is it to organize a substitute instructor?

(17) Would I be able to utilize any graduate assistants to help me with my research endeavors?

(18) How many graduate assistants work for the department?

(19) How closely do graduate assistants work with faculty members?

(20) Are there any types of research stipends available in the summer? If so, how much?

\section{Service}

(1) What are the expectations of the department with respect to service?

(2) How much emphasis is put on service in relation to teaching and research?

(3) How is service reviewed annually?

(4) What is the expectation of the department with respect to the four main service areas, namely, (i) program, (ii) department, (iii) college or university, and (iv) community? 
(5) How much service is devoted to the public schools?

(6) What scope is there for me to provide in-house consultation services?

(7) What is the policy of the department with respect to consulting for outside agencies?

(8) Are there any constraints on working with the state department?

This list is by no means exhaustive. The candidate might find that he/she is unable to ask all of these questions within the time allotted. If this is the case, the candidate always can present any unanswered questions to other individuals with whom he/she interviews.

In turn, members of the search committee might ask the candidate the following questions:

(1) What qualities will you bring to our department if you were to accept this position?

(2) What are your strengths as a teacher/researcher?

(3) What are your weaknesses as a teacher/researcher?

(4) What are your philosophies?

(5) What would be your short/long-term plans if you were to accept this position?

Be prepared to answer these questions!!!

During breakfast, lunch, or dinner, it might be a good idea to ask lighter questions (which often help to fill in any gaps in the conversation) such as the following:

\section{Miscellaneous Questions}

(1) What scope do I have for enrolling in courses?

(2) What recreational facilities are available to faculty members?

(3) What housing options are available to me?

(4) How long has each faculty member been teaching at the university?

(5) How long has the department/unit been in existence?

(6) What is the parking situation for faculty members?

\section{Relevant Questions for Department Chairperson}

Any questions that the candidate was unable to ask could be presented to the department chairperson, or other type of unit leader-assuming that the candidate is scheduled to be interviewed separately by the chairperson/unit leader. Important questions to ask the chairperson/ unit leader are:

(1) What is the philosophy of the department? 
(2) What are the long-term goals of the department?

(3) To what extent does this department conduct research in unison with other departments?

(4) On what types of committees might I be expected to serve?

(5) What type of faculty orientation is available?

(6) What scope is there for me to teach summer school?

(7) Is there a merit pay system? If so, how does this system work?

(8) What is the policy regarding tenure and promotion?

\section{Relevant Questions for the Dean}

(1) How many graduate/undergraduate students are in the college/department?

(2) When would I be expected to start work, if offered the position?

(3) What is the policy on sabbaticals?

(4) What is the policy on tenure and promotion?

(5) What is the philosophy of the college?

Candidates probably will find that the Dean of the department will give them the salary range for the position for which they are being interviewed. Thus, it is usually not necessary (and might not even be a good idea) to initiate conversations about salary. The dean also should give the candidate information, albeit brief, about health insurance, life insurance, policies for income/employment insurance (disability insurance), and pension and retirement plans.

\section{Relevant Questions for the Vice President/Provost}

Important questions to ask the vice president/provost are:

(1) What is the philosophy of the university?

(2) What is the emphasis placed on teaching, research, and service?

(3) What are the long-term goals of the university?

(4) To what extent does the university collaborate with other educational institutions, public schools, state agencies, local businesses, and the community? 


\section{Closing Comments}

Prior to the interview, candidates should find out as much information as possible about the institution for which they have applied. Much of this information can be gleaned from the institution's website. Further, candidates should determine the names and positions (e.g., titles, ranks) of every faculty member and administrator belonging to the unit (e.g., department) containing the vacant position to which they had applied. In particular, candidates should become as familiar as possible with the scholarship (e.g., research, grants) activities of each faculty member in the unit. Subsequently, the candidate could use this knowledge during the interview to fulfill several goals, including the following: (a) to give a clear message to interviewers that the candidate has prepared extremely well for the interview, which, in turn, demonstrates the candidate's interest in and enthusiasm for the position; (b) to put the candidate in a position to show how the candidate's scholarship agenda is compatible with that of the unit; (c) to put the candidate in a position to determine the faculty members whose scholarship agenda most closely aligns with her/his own agenda; and (d) to stroke the egos of the interviewers when referring to their scholarship accomplishments. Knowledge of the institution in general and the faculty members' scholarship agenda in particular likely would generate one or more questions that the candidate can add to the list presented earlier.

When evaluating responses to questions that they pose to their interviewers, candidates should not only analyze and interpret their verbal responses but, as recommended by Denham and Onwuegbuzie (2013) and Onwuegbuzie and Frels (2012a, 2012b), they should collect, analyze, and interpret nonverbal responses exhibited by the interviewers during the course of the interview. For example, candidates could use Gorden's (1980) typology of nonverbal communication data. This typology comprises the following indicators: kinesics (i.e., behaviors reflected by body displacements and postures), proxemics (i.e., behaviors denoting special relationships of the interviewees/interviewers), chronemics (i.e., temporal speech markers such as gaps, silences, hesitations), and paralinguistics (i.e., behaviors linked to tenor, strength, or emotive color of the vocal expression). For instance, with respect to silence, candidates can obtain important information from silence exhibited by their interviewers when asking them questions-indeed, sometimes more can be learned from what an interviewer does not utter than from what he/she utters.

It is probably a good idea towards the end of the interviewing process for candidates to ask either the department chair or the dean what the time frame is for notifying them, and also what form the notification will take (e.g., phone call, email). It is wise for candidates to stress to this person the importance of informing them of the decision one way or the other, because some departments are somewhat shy in divulging this piece of information to interviewees, and might, indeed, never notify the candidates, or notify them after several months. Candidates need to be assertive. Also, candidates should let the decision notifier realize the importance of their dealing with them in a professional manner.

It is also probably a good idea for candidates to present their most important questions to several of the interviewers. This is a good way to ascertain reliability of information. Candidates should remain cognizant that they are interviewing all the faculty members to the 
same extent that they are being interviewed. It is a two-way process. Therefore, candidates should not be afraid to ask questions. It is only by asking questions that they can be absolutely sure that (a) they are suitably qualified for the position and (b) that the position is suitable for them!

\section{References}

Barbera, K., Carr, J., \& Sasaki, I. (2004). Tips for getting a job in academia. Bowling Green, Ohio, US: APA Division 14, Society for Industrial and Organizational Psychology

Boehm-davis, D. A. (2004). Fast Track: Finding a position in academia. Santa Monica, California, US: Human Factors and Ergonomics Society.

Caldwell, D. F., \& Burger, J. M. (1998). Personality characteristics of job applicants and success in screening interviews. Personnel Psychology, 51, 119-136. http://dx.doi.org/10.1111/j.1744-6570.1998.tb00718.x

Caldwell, D. F., \& O’ Reilly III. C. A. (1985). The impact of information on job choices and turnover. Academy of Management Journal, 28, 934-943. http://dx.doi.org/10.2307/256246

Cook, K. W., Vance, C. A., \& Spector, P. E. (2000). The relation of candidate personality with selection-interview outcomes. Journal of Applied Social Psychology, 30, 867-885. http://dx.doi.org/10.1111/j.1559-1816.2000.tb02828.x

Denham, M. A., \& Onwuegbuzie, A. J. (2013). Beyond words: Using nonverbal communication data in research to enhance thick description and interpretation. International Journal of Qualitative Methods, 12, 670-696. Retrieved from http://ejournals.library.ualberta.ca/index.php/IJQM/article/view/19271

Ezell, H. K. (2002). Interviewing for a faculty position. American Speech-Language-Hearing Association. Retrieved from http://www.asha.org/academic/career-ladder/chap3/

Galassi, J. P., \& Galassi, M. (1978). Preparing individuals for job interviews: Suggestions from more than 60 years of research. Personnel \& Guidance Journal, 57, 188-192. http://dx.doi.org/10.1002/j.2164-4918.1978.tb05142.x

Gaugler, J. E. (2004). On the tenure track in Gerontology: I wish I had known then what I know now. Educational Gerontology, 30, 517-536. http://dx.doi.org/10.1080/03601270490445122

Geertz, C. (1973). Thick description toward an interpretive theory of culture. In C. Geertz (Ed.), The interpretation of cultures (pp. 3-30). New York, NY: Basic Books.

Gorden, R. I. (1980). Interview strategy techniques and tactics. Homewood, IL: Dorsey.

Greene, C., Caracelli, V. J., \& Graham, W. F. (1989). Toward a conceptual framework of mixed-method evaluation designs. Education Evaluation and Policy Analysis, 11, 
255-274. http://dx.doi.org/10.3102/01623737011003255

Kisamore, J. L., Casper, W. J., Martin, J. A., \& Hall, S. M. (2004). More tips for obtaining a job in academia. Bowling Green, Ohio, US: APA Division 14, Society for Industrial and Organizational Psychology.

Legard, R., Keegan, J., \& Ward, K. (2003). In-depth interviews. In J. Ritchie \& J. Lewis (Eds.), Qualitative research practice: a guide for social science students and researchers (pp. 138-169). Thousand Oaks, CA: Sage.

McCarthy, J., \& Goffin, R. (2004). Measuring job interview anxiety: Beyond weak knees and $\begin{array}{llll}\text { sweaty palms. Personnel } & \text { Psychology, 637. }\end{array}$ http://dx.doi.org/10.1111/j.1744-6570.2004.00002.x

Onwuegbuzie, A. J., \& Frels, R. K. (2012a, June). A mixed research framework for collecting and analyzing nonverbal communication data in interviews. Paper presented at the International Mixed Methods Conference, Leeds, England.

Onwuegbuzie, A. J., \& Frels, R. K. (2012b, May). Mixed research techniques for collecting and analyzing nonverbal communication data in qualitative interviews. Paper presented at the Eighth International Congress of Qualitative Inquiry, Urbana-Champaign, IL.

Paul, R., \& Elder, L. (2006). The art of Socratic questioning. Dillon Beach, CA: Foundation for Critical Thinking.

Rubin, H. J., \& Rubin, I. S. (2005). Qualitative interviewing: The art of hearing data (2nd ed.). Thousand Oaks, CA: Sage.

Schmit, M. J., Amel, E. L., \& Ryan, A. (1993). Self-reported assertive job-seeking behaviors of minimally educated job hunters. Personnel Psychology, 46, 105-124. http://dx.doi.org/10.1111/j.1744-6570.1993.tb00869.x

Sieverding, M. (2009). 'Be cool!': Emotional costs of hiding feelings in a job interview. International Journal of Selection \& Assessment, 17, 391-401. http://dx.doi.org/10.1111/j.1468-2389.2009.00481.x

Stasny, E. A. (2001). How to get a job in academics. The American Statistician, 55(1), 35-40. http://dx.doi.org/10.1198/000313001300339914

Young, M. J., Behnke, R. R., \& Mann, Y. M. (2004). Anxiety patterns in employment interviews. Communication Reports, 17(1), 49-57. http://dx.doi.org/10.1080/08934210409389373

\section{Copyright Disclaimer}

Copyright reserved by the author(s).

This article is an open-access article distributed under the terms and conditions of the Creative Commons Attribution license (http://creativecommons.org/licenses/by/3.0/). 